\title{
The Prevalence of Fibroma in Oral Mucosa Among Patient Attending USM Dental Clinic Year 2006-2010
}

\author{
Daddy Suradi Halim \\ Abdullah Pohchi \\ Pang EE Yi \\ School of Dental Sciences, Universiti Sains Malaysia, \\ 16150 Kubang Kerian, Kelantan, Malaysia. \\ E-mail: daddy@kb.usm.my \\ Received August 15, 2010; Accepted September 20, 2010
}

\begin{abstract}
The purpose of this preliminary retrospective study was to determine the prevalence of fibroma in oral mucosa among patients attending USM dental clinic from 1/6/2006-1/6/2010. Fibroma of the oral mucosa is the most common benign tumor of the oral cavity. It is a reactive hyperplasia of fibrous connective tissue in response to local irritation or trauma. A lesion on any part of the oral mucosa have a broad differential diagnosis ranging from traumatic lesions (mucocele), neurogenic lesions (neurofibromatosis), lipoma, epithelial tumors (squamous papilloma) and inflammatory/reactive hyperplasia of soft tissue (pulp polyp). A total number of 192 patients ( 82 male and 110 female) who are registered in the Oral Medicine and Oral Pathology Log Book were included in this study regardless of their age, $16 \%$ of them were diagnosed to have fibroma and out of that, $29 \%$ of them were male and $79 \%$ female. The peak incidence of the lesion was in the $3^{\text {rd }}$ decade of life. The lesions occurred in the tongue, lip mucosa, sulcus region and buccal mucosa were each to be $12.9 \%$, $12.9 \%, 32.2 \%$ and $41.9 \%$. This study shows that fibroma is one of the common oral mucosal lesion and it occurred mostly in the $3^{\text {rd }}$ decade of life where the prevalence is higher in female patients.
\end{abstract}

Keywords: Fibroma, gender dependence

\section{Introduction}

Fibromas are benign tumors that are composed of fibrous or connective tissue. They can grow in all organs, arising from mesenchyme tissue. When the term fibroma is used without modification, it is usually considered benign.

Oral Mucosa is the mucous membrane epithelium of the mouth. It can be divided into three categories):

i. Masticatory mucosa - keratinized stratified squamous epithelium, found on the dorsum of the tongue, hard palate and attached gingiva.

ii. Lining mucosa - non-keratinized stratified squamous epithelium, found almost everywhere else in the oral cavity. iii. Specialized mucosa - specifically in the regions of the taste buds on the dorsum of the tongue.

\subsection{Clinical features of fibroma of oral mucosa}

Fibroma of the Oral mucosa is the most common "tumour" of the oral cavity/Benign Neoplasm derived from fibrous connective tissues (Oral and Maxillofacial Pathology.Neville et al.2009). From one of the study by Domingo et al (2007), of the 300 benign tumors of the oral mucosa studied, 53.3\% were diagnosed as fibroma. It is also known as Irritational Fibroma/Traumatic Fibroma/Focal 
Fibrous Hyperplasia/Fibrous Nodule/Fibroepithelial Polyp according to Toida et al in 2001. However, it is doubtful that it represents a true neoplasm in most instances; rather, it is a reactive hyperplasia of fibrous connective tissue in response to local irritation or trauma. Although the irritation fibroma can occur anywhere in the mouth, the most common location is the buccal mucosa along the bite line. Presumably, this is a consequence of trauma from biting the cheek. The labial mucosa, tongue and gingiva also are common sites (http://emedicine.medscape.com/ article/1080948-overview). It is likely that many gingival fibromas represent fibrous maturation of a preexisting pyogenic granuloma. The lesion typically appears as a smooth-surfaced pink nodule that is similar in color to the surrounding mucosa. In black patients, the mass may demonstrate gray brown pigmentation. In some cases the surface may appear white as a result of hyperkeratosis from continued irritation. Most fibromas are sessile, although some are pedunculated. They range in size from tiny lesions that are only a couple of millimeters in diameter to large masses that are several centimeters across. However, most fibromas are $1.5 \mathrm{~cm}$ or less in diameter. The lesion usually produces no symptoms, unless secondary traumatic ulceration of the surface has occurred. Irritation fibromas are most common in the fourth to sixth decades of life and the male-to female ration is almost 1:2 for cases submitted for biopsy. The frenal tag is a commonly observed type of fibrous hyperplasia, which most frequently occurs on the maxillary labial frenum. Such lesions present as small, asymptomatic, exophytic growths attached to the thin frenum surface. Totally harmless unless they interfere with normal functioning and they are not contagious.

\subsection{Histopathologic features of fibroma of oral mucosa}

Microscopic examination of the irritation fibroma shows a nodular mass of fibrous connective tissue covered by stratified squamous epithelium. This connective tissue is usually dense and collagenized, although in some cases it is looser in nature. The lesion is not encapsulated; the fibrous tissue instead blends gradually into the surrounding connective 62 tissues. The collagen bundles may be arranged in a radiating, circular or haphazard fashion. The covering epithelium often demonstrates atrophy of the rete ridges because of the underlying fibrous mass. However, the surface may exhibit hyperkeratosis from secondary trauma. Scattered inflammation may be seen, most often beneath the epithelial surface. Usually this inflammation is chronic and consists mostly of lymphocytes and plasma cells.

\subsection{Treatment and prognosis}

The irritation fibroma is treated by conservative surgical excision. Recurrence is extremely rare. However, it is important to submit the excised tissue for microscopic examination because other benign or malignant tumors may mimic the clinical appearance of a fibroma. Because frenal tags are small, innocuous growths that are easily diagnosed clinically, no treatment is usually necessary.

\section{Materials and Methods}

This is a retrospective preliminary study. A total number of 192 adults and children patients whose name were recorded in the Oral Medicine and Oral Pathology Log Book (year 2006-2010) were being taken as subjects. The inclusion criteria was patients with fibroma in oral mucosa and there is no exclusion criteria for the subjects. Ethical approval was obtained from the Research and Ethics Committee, Universiti Sains Malaysia in April 2009.

Patients Name, Age of Diagnosis, RN, Gender, Race, Address, Referred from, Clinical Diagnosis, Histopahtological Description and Location of Fibroma are recorded in a form. The process of data collection done manually by hand writing at the Craniofacial lab where the OMOP Log Book record were kept. Some of the patients details were not complete, so patients folder being traced at the Folder Unit to complete the incompleted.

After the collection of the data, the hand written data was being transferred into various table and graph forms using the Microsoft Word software to be analysed using the SPSS softwaren version 12 . Results were expressed as frequencies and percentages. 


\section{Results}

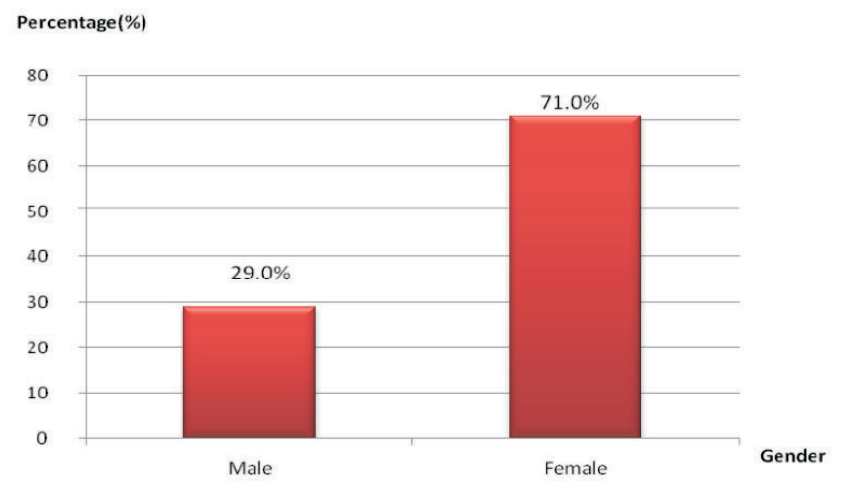

Figure 1 . Gender distribution of the subjects with fibroma.

Figure 1 shows gender distribution of the subjects with fibroma. There were a total of 192 patients recorded in the oral medicine and oral pathology log book and out of that $192,29 \%(n=9)$ of males and $71 \%(n=22)$ of females being diagnosed of having oral mucosa fibroma. Which means fibroma patients give a total number of $31(16 \%)$ overall. The age of all the total subjects ranged from 4-81 years old with the mean age of 33.41 and standard deviation of 19.35 .

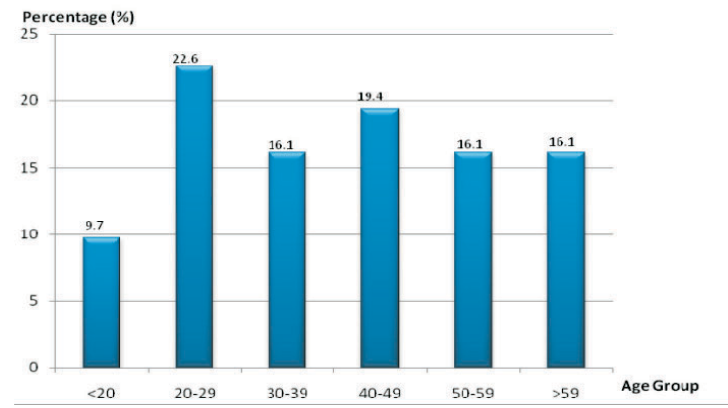

Figure 2. Age distirbution of the subjects with fibroma.

Figure 2 shows the age distribution of the subjects with fibroma. The total 31 fibroma patients were ranged form 14-65 years old and they were being classified into 6 main groups based on the study done by Toida et all 2001. Most of the patients were diagnosed with fibroma were in the age group between 20-29 (22.6\%) whereas the least age group was $<20$ (9.7\%). Age group 30-39, 50-59 and $>59$ were equally the same which was $16.1 \%$. Age group 40-49 has the total number of 6 patients (19.4\%). The study shows that the peak incidence was in the $3^{\text {rd }}$ decade of life whereas the mean age of fibroma patients was 41.48 with the standard deviation of 16.74 .

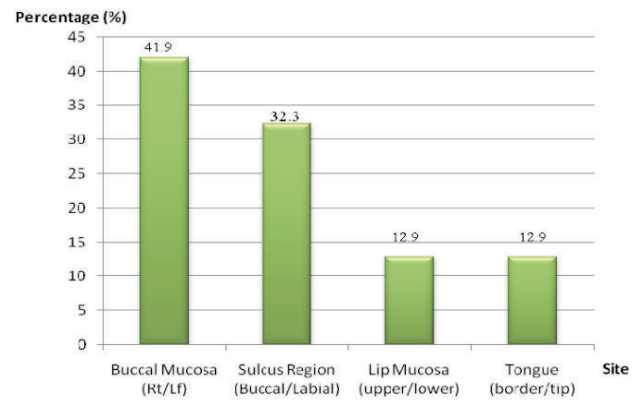

Figure 3. Site of occurence of lesion

Figure 3 shows the occurrence of Fibroma at different sites of the oral mucosa. The lesions occurred on buccal mucosa was to be $41.9 \%(n=13)$, on sulcus region $32.3 \%(n=10)$, on lip mucosa $12.9 \%$ $(n=4)$ and on tongue was also $12.9 \%(n=4)$. From here, it shows that fibroma commonly occurred on buccal mucosa without considering either on the right side or left side and least on tongue also without considering either on the tip of the tongue or border of the tongue. 
Table 1. Gender Age Specific in Fibroma

\begin{tabular}{|c|c|c|c|c|c|}
\hline & \multirow[t]{2}{*}{ Variables } & \multicolumn{2}{|c|}{ Frequency $(\mathrm{N})$} & \multirow{2}{*}{$\begin{array}{l}X^{2} \text { Statistic } \\
\text { (df) }\end{array}$} & \multirow[t]{2}{*}{$p$ value } \\
\hline & & $\begin{array}{l}\text { Fibroma } \\
\text { Present } \\
\mathrm{n}(\%)\end{array}$ & $\begin{array}{l}\text { Fibroma } \\
\text { Absent } \\
\mathrm{n}(\%)\end{array}$ & & \\
\hline Age & $<20$ & $3(9.7)$ & 61 (37.9) & $9.752^{\mathrm{a}}(5)$ & 0.083 \\
\hline \multirow[t]{5}{*}{ Group } & $20-29$ & $7(22.6)$ & $28(17.4)$ & & \\
\hline & $30-39$ & $5(16.1)$ & $19(11.8)$ & & \\
\hline & $40-49$ & $6(19.4)$ & $17(10.6)$ & & \\
\hline & $50-59$ & $5(16.1)$ & 17 (10.6) & & \\
\hline & $>59$ & $5(16.1)$ & $19(11.8)$ & & \\
\hline \multirow[t]{2}{*}{ Gender } & Male & $9(29)$ & $74(46)$ & $3.036^{\mathrm{a}}(1)$ & 0.081 \\
\hline & Female & $22(71)$ & $87(54)$ & & \\
\hline
\end{tabular}

$\mathrm{a}=$ Chisquare test

Figure 4 shows the occurrence of fibroma among different races. In this study, the races were being divided into mainly 2 categories which were the Malays and others (which included the Chinese, Indian, and others). This is because the number of subjects who being diagnosed of having fibroma are not sufficient. $80 \%(n=25)$ of the fibroma patients were Malays whereas $19.4 \%(n=6)$ were the Chinese. The total number of Malay patients are 160, Chinese 30 and 2 foreign patients.

Table 1 shows age and gender specific association with the occurrence of fibroma. There was some differences in the occurrence of fibroma at different age group. Fibroma patients were found more in the 20-29 age group where $n=7(22.6 \%)$ compare to the others. However Table 1 shows that the difference was not statistically significant as $p$-value $=0.083$ which suppose to be $<0.05$ to be significant. This study shows no association between the occurrence of fibroma with the age group. Besides that, it shows that there was a big difference in fibroma occurrence between male and female. However, the difference was not significant as $p$-value $=0.081$. This also tells that there is no association between occurrence of fibroma with Gender.

\section{Discussion}

According to one of the study done by Toida et all (2001), they found out that most of the fibroma lesions occurred in patients at the $6^{\text {th }}$ decade of life. While in our study, we found out that most of the fibroma lesions occurred at the $3^{\text {rd }}$ decade of life which this is different from their studies. Besides that they also found out that 66 lesions were on tongue, 42 lesion on buccal mucosa and 7 cases on hard palate whereas in our studies, most of the lesions were found on the buccal mucosa (41.9\%), followed by the sulcular region (32.3\%) and $12.9 \%$ each for the lip mucosa and tongue.

In another studies done by Domingo et al (2007), of the 300 benign oral mucosa tumors studied, 160 (53.3\%) were diagnosed as fibroma which means fibroma is a popular lesions in the oral mucosa. These findings are similar to those obtained in this present study where fibroma in oral mucosa is the $2^{\text {nd }}$ commonest oral mucosa pathology after mucocele. They also found that in that total 160 fibroma patients , 105 (65.60\%) of them were female whereas the rest were male $(55,34.40 \%)$.The study 
shows that there is a higher prevalence among females in the case of fibroma. This result is similar to ours where in our studies, fibroma commonly occurs in females which is $71 \%$ then in male which is only $29 \%$ of the total fibroma patients.

In the studies done by Pour et al (2008), the most common lesion in fibrous lesions group was the fibroma (78 cases, $30 \%$ ) and the peak was in the 20 29 years old age group (16 cases, 6.18\%). This supports our finding where the peak incidence also occurred at the 20-29 years old group (7, 24.14\%). And in their studies, fibroma occurred more commonly in females then in the males.

From the study we knew that oral mucosa fibroma is a common site that response to trauma from teeth or dental prostheses. In the other words, oral mucosa fibroma occurs whenever there is trauma to the affected mucosa where accidental biting probably accounts for most of these lesions. A fibroma may occur at any oral site, but it is seen most often on the buccal mucosa along the plane of occlusion of the maxillary and mandibular teeth according to website Emedicine Medscape because these is the place where the teeth are biting together and repetitive biting / irritation to this region can cause the occurrence of fibroma. This is to show that in our study, it tells that why in our study, most of the oral mucosa fibroma were found in the buccal mucosa region (either the right buccal mucosa or left buccal mucosa) as shown in Figure 3 where $41.3 \%$ of the oral mucosa fibroma were found at buccal mucosa region.

In our study we found out that most of the oral mucosa fibroma cases occurred in the $3^{\text {rd }}$ decade of life. One of the cause of Oral mucosa fibroma is due to cheek/lip/tongue biting and stress and anxiety can trigger the cheek biting (www.wrongdiagnosis.com). So, a person take up cheek, lip and tongue biting is due to stress or anxiety. And as what we know, people between the age of 20-29 faces lots of changes and obstacles which cases them to have more stress and anxiety. This is because, most of them are venturing into young adulthood and they are new to the working world. The have to learn to be independent economically to survive in this world. All these causes them to have more stress compare to the other age group. And from here it tells that why oral mucosa fibroma was commonly found in the the $3^{\text {rd }}$ decade of life in our study.

Besides that, the prevalence of oral mucosa fibroma is higher in female (71\%) then male (29\%) (Figure1). According to the website Family Education, stress is common to women because women are capable of doing many things at once, they are more susceptible to the stresses of all the activities they take on. Women are social organizers, mediators, planners, mothers, wives, spouses, girlfriends, daughters, friends, athletes, teammates, managers, employees, cleaning ladies, cooks, partners, athletes, and therapists. Besides stress, Hormonal fluctuations in female can be a source of stress in girls and women. This varies in intensity from one person to the next, but it is quite common. Premenstrual syndrome (PMS) can include feeling sad, hopeless, suicidal; tense, anxious, tearful, irritable, anger affecting others, disinterest in daily activities and relationships, trouble concentrating, fatigue, low energy; food cravings, sleep disturbances, and feeling out of control. Physical symptoms include appetite changes, bloating, breast tenderness, headaches, and joint or muscle pain. All these can add on to the stress of a woman and this tells that why oral mucosa fibroma is higher among females than males.

In this study, we also found out that most of the oral mucosa fibroma patients are the Malays which is $80.6 \%$ of them compare to the others which is only $19.4 \%$ of them. $95 \%$ of Kelantan's population are ethnic Malay (source from Wikipedia) that's why the occurrence of oral mucosa fibroma is high among the Malays compare to the others.

The fibroma cases in this study are diagnosed mainly base on the histological features of the given section. The given section will shows stratified squamous epithelium and this epithelium shows hyperkeratosis \& parakeratosis. The underlying connective tissue is fibrocollagenous \& papillomatosis \& contains scattered blood vessels. So far, none of the fibroma case transform to malignant case. Clinically, majority of the cases were found accidentally by dental student during dental check-up. It was also commonly found in patient wearing denture. However there are also cases which were due to trauma after tooth extraction or nonspecific trauma. 
After all, we found out that there is no association between fibroma with age group and sex of patient. This means, there is no particular age or sex of patient that will get fibroma.

\section{Conclusion}

In conclusion, our study revealed that oral mucosa fibroma is a common lesion occurred among patients in Dental clinic HUSM from 1/6/2006-1/6/2010 females are more prevalence compare to male. Besides that most of the fibroma cases occurred in the $3^{\text {rd }}$ decade of life and majority of them present at the buccal mucosa.

\section{References}

1. Toida M, Murakami T, Kato K, Kusunoki Y, Yasuda S, Fujitsuka H, Ichihara H, Watanabe F, Shimokawa $\mathrm{K}$ and Tatematsu N. 2008. Irritational fibroma of the oral mucosa:A clinicopathological study of 129 lesions in 124 cases. Oral Med Pathol;6:9194.

2. Terres-Domingo $S$, Bagan JV, Jimenez $Y$, Poveda R, Murillo J, Diaz JM, Sanchis JM, Gavalda C and Carbonell E. 2008. Benign tumors of the oral mucosa: A study of 300 patients. Med Oral Patol Oral Cir Bucal March 1, 13(3):E161-6
3. Pour M.A.H., Rad M, and Mojtahedi A. 2008.A survey of Soft Tissue Tumor-Like Lesions of Oral Cavity: A clinicopathological Study. Iran Journal Of Pathology 3 (2):81-87

4. Mumcu G, Cimilli $\mathrm{H}$, Sur $\mathrm{H}$, Hayran $\mathrm{O}$ and Atalay T. 2005. Prevalence and distribution of oral lesions: a cross sectional study in Turkey. Oral Diseases 11:81-87

5. Mathew A.L. , Pai K.M. , Sholapurkar A.A. and Vengal M. 2008.The prevalence of oral mucosal lesions in patients visiting a dental school in Southern India. Indian J Dent Res, 19(2)

6. Kintarak S and Kietthubthew S. 2006. .A nodular mass of the anterior palatal gingiva. Oral Surg Oral Med Oral Pathol Oral Radiol Endod 102:3-6

7. Cebeci ARI, Gulsahi A, Kamburoglu K, Orhan BK and Oztas B. 2009. Prevalence and distribution of oral mucosal lesions in an adult turkish population. Med Oral Patol Oral Cir Bucal. Jun 1;14 (6):E272-7.

8. Ntomouchtsis A, Karakinaris $G$, Poulolpoulos A, Kechagias N, Kittikidou K, Tsompanidou C, Vahtsevanos K and Antoniades K. 2010. Benign lip lesions. A 10 year retrospective study. Oral Maxillofac Surg, DOI 10.1007/s10006-009-0196$y$

9. Neville B., Damm DD, Allen CM , Bouquot J and Neville BW. 2009. Oral And Maxillofacial Pathology, $3^{\text {rd }}$ ed. United Kingdom: Saunders Elsevier. 